\title{
Radiosensibilisierung
}

\section{Verstärkung der Strahlenwirkung durch Checkpoint-Kinase-Inhibitor}

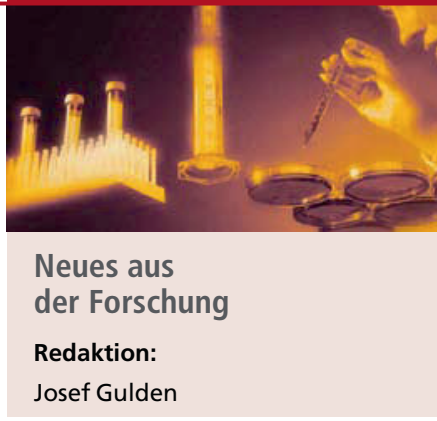

Substanzen, die die Strahlenempfindlichkeit von Tumorzellen selektiv erhöhen, ohne normale Zellen zu beeinflussen, stehen auf der Wunschliste von Strahlentherapeuten ganz oben. Die Verbindung AZD7762, die bei der Zellteilung aktive Checkpoint-Kinasen hemmt und dadurch die DNA-Reparatur nach Strahlenschäden inhibiert, wurde am National Cancer Institute in Bethesda in Zellkulturen und in Mäuse-Tumormodellen getestet. Alleine gegeben beeinflusste AZD7762 Tumorzellen praktisch nicht, aber in Kombination mit ionisierender Strahlung wurde deren zytotoxische Wirkung auf die Zellen, insbesondere auf solche mit mutiertem p53-Tumorsuppressor-Gen, um 60-70\% erhöht. Normale menschliche Fibroblasten blieben hingegen unbeeinflusst. Auch in Mäusen mit menschlichen Kolonkarzinomen erhöhte AZD7762 die Wirkung von Bestrahlung signifikant.

Mitchell JB et al. In vitro and in vivo radiation sensitization of human tumor cells by a novel checkpoint kinase inhibitor, AZD7762. Clin Cancer Res 2010; 16 [Epub ahead of print, DOI 10.1158/1078-0432.CCR-09-3277].

\section{Wo kommen hämatopoetische Stammzellen eigentlich her? Wenn Endothelzellen wieder dedifferenzieren und zu Stammzellen werden}

Dass Blutstammzellen des Menschen aus dem Knochenmark stammen, ist für Hämatologen eine Binsenweisheit. Dies gilt für alle adulten Vertebraten. Dass ihr ontogenetischer Ursprung im frühen Embryo aber in der Aorta-Gonaden-Mesonephros-Region liegt, ist wohl weniger bekannt. Sie entstehen dort unter dem Einfluss des Transkriptionsfaktors Runx1 aus Endothelzellen der Aorta. Diesen Prozess haben Molekularbiologen und Pathologen an der University of Auckland in Neuseeland nun in eindrucksvollen mikroskopischen Bildern beim transgenen Zebrafisch nachzeichnen können: Die transparenten Embryonen des Zebrafisches waren gentechnisch so manipuliert, dass u.a. das Gen für grünes fluoreszierendes Protein (GFP) an das Runx1-Gen gekoppelt war. Zugleich mit Runx1 wurde daher GFP exprimiert und damit die Fluoreszenzmarkierung der hämatopoetischen Stammzellen ,eingeschaltet", die sich im ventralen Endothel der dorsalen Aorta bilden (Abb. 1a).

Diese Zellen runden sich $\mathrm{ab}$, reichern sich vorübergehend im subaortalen Raum an und gelangen schließlich über die Schwanzvene in die Zirkulation. Ihr Weg ließ sich bis zu Thymus (Abb. 1b) und Niere nachverfolgen, wo beim entwickelten Fisch die Hämatopoese stattfindet.

Interessant für den Hämatologen ist vor allem die Aussicht, die molekularen Mechanismen im
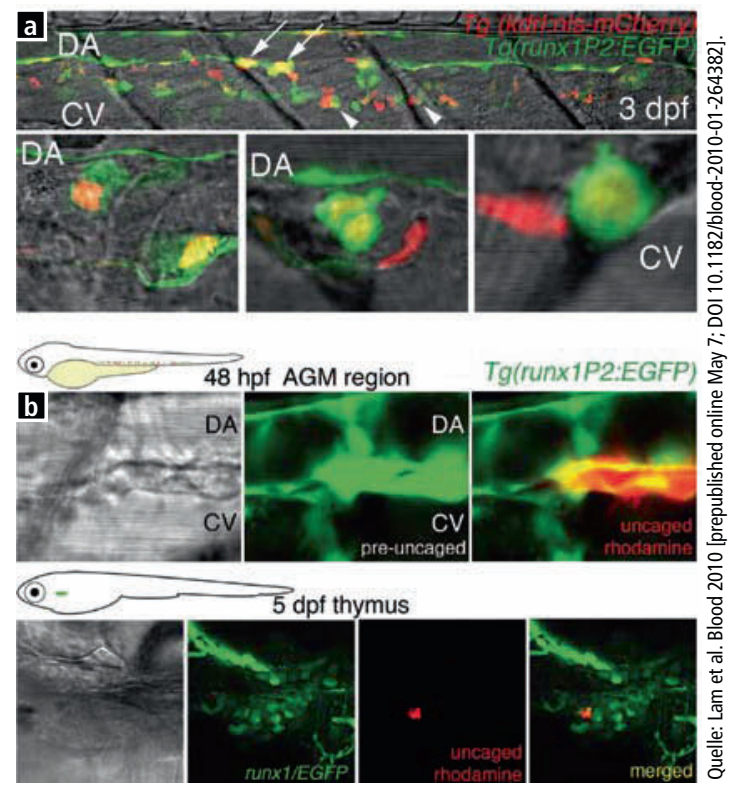

Abbildung 1. Zellen mit einer roten Markierung für Endothelzellen und der grünen Markierung für Runx1/GFP zeigen sich drei und vier Tage nach Befruchtung im Zebrafisch-Embryo ventral der dorsalen Aorta (DA), in der Schwanzvene (CV, Abb. a und obere Reihe in Abb. b) und nach fünf Tagen im Thymus (untere Reihe in Abb. b). hpf: hours post fertilization, dpf: days post fertilization.
Detail aufzuklären, durch die aus einer offensichtlich funktionellen und differenzierten Subpopulation von Endothelzellen die hämatopoetischen Stammzellen entstehen.

Lam EY et al. Live imaging of Runx1 expression in the dorsal aorta tracks the emergence of blood progenitors from endothelial cells. Blood 2010 [prepublished online May 7; DOI 10.1182/blood-2010-01-264382]. 